\title{
Serum triglyceride level in type 2 diabetes mellitus patients with or without Frozen shoulder
}

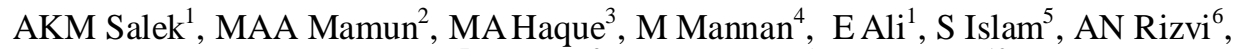 \\ AZChowdhury $^{7}$, J Islam ${ }^{8}$, MH Rahman ${ }^{9}$, C Ferdous ${ }^{10}$ \\ ${ }^{I}$ Department of Physical Medicine and Rehabilitation, BSMMU, Dhaka, ${ }^{2}$ Chi Research \& Infotec Ltd, \\ Dhaka $;{ }^{3}$ Medical Statistics, BSMMU, Dhaka $;{ }^{4}$ Department of Radiology and Imaging, United Hospital, \\ Dhaka; ${ }^{5}$ Dhaka City Corporation, Dhaka $;{ }^{6}$ Department of Neurology, BSMMU, Dhaka; ${ }^{7}$ Department of \\ Orthopedics BSMMU, Dhaka; ${ }^{8}$ Department of Neurosurgery, Shahid Suhrawardi Medical College, Dhaka; \\ ${ }^{9}$ Department of Urology, BSMMU, Dhaka $;{ }^{10}$ Bangladesh Institute of Health Science, Dhaka.
}

\begin{abstract}
Background: Musculoskeletal disorders are very common among the diabetic patients and frozen shoulder is one of the disabling conditions. The present study was conducted to compare the serum triglyceride level among the patients of type 2 diabetic presented with and without frozen shoulder. Methodology: This case control study was conducted from January 2008 to December 2009, in the department of Physical Medicine and Rehabilitation, Bangabandhu Sheikh Mujib Medical University (BSMMU), Dhaka with an aim to compare the serum triglyceride level among diabetic patients presented with, and without frozen shoulder. Thirty types 2 diabetic patients with frozen shoulder were selected as cases and similar number well matched type 2 diabetic patients without frozen shoulder were selected as control. Results: We prospectively studied 30 diabetes mellitus (type 2) patients with the diagnosis of frozen shoulder. The blood sugar both fasting and 2 hours after breakfast, HbA1c and serum triglyceride levels were measured in all patients and compared with those in 30 diabetic patients without frozen shoulder. The blood sugar, fasting and 2 hours after breakfast, HbA1C and serum triglyceride levels were significantly elevated in the frozen-shoulder group (fasting blood sugar $\mathrm{p}=$ 0.012 ; blood sugar 2 hours after breakfast $\mathrm{p}<0.01 ; \mathrm{HbA}_{1 \mathrm{C}} \mathrm{p}<0.05$; and triglyceride $\mathrm{p}<$ 0.001).Conclusion: Diabetic type 2 patients presented with frozen shoulder had higher serum triglyceride level compare to the diabetic type 2 patients without frozen shoulder.
\end{abstract}

\section{Introduction}

Frozen shoulder is a disabling but easily manageable condition in the primary health care setting, characterized by pain and loss of movement ${ }^{1,2}$. The term 'frozen shoulder' was first introduced by Codman in 1934 and described a painful shoulder condition of insidious onset that was associated with stiffness and difficulty of sleeping on the affected side. Long before Codman, in 1872, the same condition had already been labelled 'peri-arthritis' by Duplay. In 1945, Naviesar coined the term 'adhesive capsulitis', Frozen shoulder is a condition difficult to define, treat, and explain from the point of view of pathology $\mathrm{y}^{3}$.

Frozen shoulder usually present in the sixth decade of life, and onset before the age of $40 \mathrm{y}$ is very uncommon. The peak age is 56y, and the condition occurs slightly more often in women than men ${ }^{4}$. Approximately $70 \%$ of patients presenting with adhesive capsulitis are women; however, the role of sex in the etiology, development, and outcome of treatment remains unclear $5^{5}$. The aetiology remains unknown although some aspects of the pathophysiology have recently been documented. The symptoms are generally self-limiting over one to three years ${ }^{6}$. Recurrence is highly unusual. Patients usually recover, but they may never regain their full range of movement ${ }^{1}$.

There are associations with many medical conditions, the strongest being that with diabetes in which the incidence is reported as being between two and four times higher than that in the normal population $^{6}$. Older people with diabetes demonstrate accelerated loss of skeletal muscle mass and strength and have considerable functional impairment associated with reduced health status. Diabetes is a known risk factor for frozen shoulder ${ }^{7}$. The association of diabetes and frozen shoulder is well documented, $17.9 \%$ in diabetics compared to $7 \%$ in non-diabetics ${ }^{8}$. 
Evaluation of patients with shoulder disorders often presents challenges ${ }^{9}$. Despite research in the last century, the etiology and pathology of frozen shoulder is remains enigmatic ${ }^{10}$. True frozen shoulder has a protracted natural history that usually ends in resolution ${ }^{1}$. Diagnosis of frozen shoulder based on the patient's symptoms and a physical examination. X-rays or MRI (magnetic resonance imaging) studies are sometimes used to rule out other causes ${ }^{3}$.

\section{Methodology}

Serum triglycerides levels of 30 patients with type 2 diabetes mellitus having frozen shoulder were evaluated and compared with that of another 30 diabetic patients without frozen shoulder. Diabetic patients having frozen shoulder attended in the Department of Physical Medicine and Rehabilitation, Bangabandhu Sheikh Mujib Medical University (BSMMU) during the period of January 2008 to December 2009 were enrolled as case and 30 diabetic patients with musculoskeletal problems other than idiopathic frozen shoulder were enrolled as control. All of these patients were selected randomly. Frozen shoulder was diagnosed clinically on the basis of the presence of both active and passive restrictions of the glenohumeral joint in flexion, abduction and internal rotation, with external rotation restricted to less than $50 \%$ of the normal side with the arm at the side. 'Frozen shoulder' is a condition of gradual onset, pain felt near the insertion of the deltoid, inability to sleep on the affected side, painful and incomplete elevation and external rotation, and a normal radiological appearance first described by Codman $^{11}$. All our patients fulfilled these criteria, and also had reduction of both active and passive movement. Patients with frozen shoulder secondary to soft tissue trauma, fracture, arthritis, hemiplegia or any other known causes were excluded from the study.

All patients were fasted overnight for 12 hours before venepuncture for the measurement of serum triglyceride, blood sugar (fasting) and HbAlc. Two hours after breakfast all were again tested for blood sugar again.

Continuous variables are expressed as mean \pm SD and compared with both groups by Student's t test and categorical variables are presented as frequency and percentage and compared with both groups by the chi-square test. Risk ratio with $95 \%$ confidence interval was calculated. All reported $\mathrm{P}$ values were two-sided and $\mathrm{P}<0.05$ was considered significant. The statistical tests were performed using Statistical Package for the Social Sciences
(SPSS) version 12 (version 12.0; SPSS Inc, Chicago, IL, USA).

\section{Results}

Total 30 diabetic patients with frozen shoulder as case and 30 diabetic patients without frozen shoulder as control were included in this study. Out of 30 patients $10(33.3 \%)$ had right sided, 14 $(46.7 \%)$ had left sided, and $6(20.0 \%)$ had bilateral frozen shoulder. Average age of the patients of both groups was 56.77 (SD 8.07) years (Table I).

Mean duration of frozen shoulder was 2.07 months (SD 0.52) and maximum $56.7 \%$ had complaints of suffering from 6 to 12 months.

The triglyceride concentration in the frozen shoulder group was $200.13 \mathrm{mg} / \mathrm{dL}$ (SD 21.26) and in control group $140.03 \mathrm{mg} / \mathrm{dL}(\mathrm{SD} 12.58)(\mathrm{p}<0.001$, Student's t-test) (Table II).

The mean blood sugar both fasting and 2 hours after breakfast was $7.25 \mathrm{mmol} / \mathrm{L}$ (SD .96) and 8.54 $\mathrm{mmol} / \mathrm{L}$ (SD 0.954) respectively compared with $6.67 \mathrm{mmol} / \mathrm{L}$ (SD0.76), and $7.86 \mathrm{mmol} / \mathrm{L}$ (SD 0.88) respectively in the control patients $(p=0.012$ and $\mathrm{p}=0.006$ respectively, student's t-test). The mean HbA1c in frozen shoulder group was 7.15 (SD 0.77 ) and in control group 6.77 (SD 0.51) ( $\mathrm{p}=0.028$, Student's t test) (Table III).

Table I: Frozen shoulder and duration of symptom $(\mathrm{n}=30)$

\begin{tabular}{lcc}
\hline & Frequency & Percentage \\
\hline Affected shoulder & & \\
Right side & 10 & 33.3 \\
Left side & 14 & 46.7 \\
Bilateral & 06 & 20.0 \\
$\begin{array}{l}\text { Duration of symptoms (Mean } \pm \text { SD) } \\
\text { (months) }\end{array}$ & $8.30 \pm 3.40$ & \\
\hline
\end{tabular}

Table II: Triglyceride level and frozen shoulder

\begin{tabular}{lcc}
\hline Level of TG & $\begin{array}{c}\text { DM with Frozen } \\
\text { shoulder }(\mathrm{n}=30)\end{array}$ & $\begin{array}{c}\text { DM without Frozen } \\
\text { shoulder }(\mathrm{n}=30)\end{array}$ \\
\hline Normal $(<150 \mathrm{mg} / \mathrm{dl})$ & $0(0)$ & $19(63.3)$ \\
Abnormal $(\geq 150 \mathrm{mg} / \mathrm{dl})$ & $30(100)$ & $11(36.7 \%)$ \\
\hline Total & $30(100.0)$ & $30(100.0)$ \\
\hline
\end{tabular}

Odd ratio $(95 \% \mathrm{CI})=3.73(2.25,6.18) ; \mathrm{p}$ value $=0.002($ chi square test)

Table III: Blood glucose and $\mathrm{HbA} 1 \mathrm{C}$ level of the patients of both groups

\begin{tabular}{|c|c|c|c|}
\hline Mean \pm SD & $\begin{array}{l}\text { DM with } \\
\text { Frozen shoulder }\end{array}$ & $\begin{array}{l}\text { DM without } \\
\text { Frozen houlder }\end{array}$ & $\begin{array}{l}\mathrm{P} \\
\text { value }^{\#}\end{array}$ \\
\hline $\begin{array}{l}\text { Fasting glucose } \\
(\mathrm{mmol} / \mathrm{L})\end{array}$ & $7.25 \pm 0.96$ & $6.67 \pm 0.76$ & 0.012 \\
\hline $\begin{array}{l}2 \text { hours ABF } \\
(\mathrm{mmol} / \mathrm{L})\end{array}$ & $8.54 \pm .954$ & $7.86 \pm 0.88$ & 0.006 \\
\hline $\mathrm{HbA1C}(\%)$ & $7.15 \pm 0.77$ & $6.77 \pm 0.51$ & 0.028 \\
\hline $\begin{array}{l}\text { Serum triglyceride } \\
(\mathrm{mg} / \mathrm{dl})\end{array}$ & $200.13 \pm 21.26$ & $144.03 \pm 12.58$ & $<0.001$ \\
\hline
\end{tabular}

\# $\mathrm{P}$ value was derived from unpaired $\mathrm{t}$ test was done. 


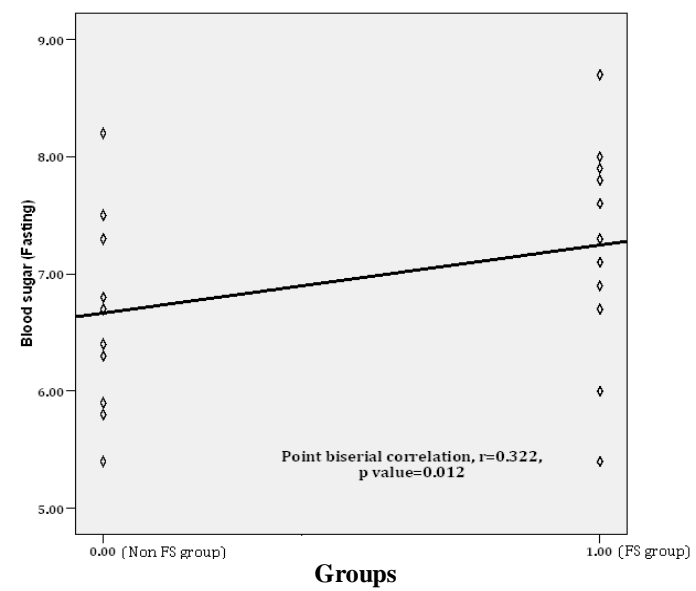

Figure 1: Correlation between fasting blood sugar and groups Here blood sugar level is continuous variable and group is a categorical variable $(0=$ Non frozen shoulder [non-FS], $1=$ Frozen shoulder [FS] group). So, Point biserial correlation is appropriate to measure the correlation of above mentioned variables.

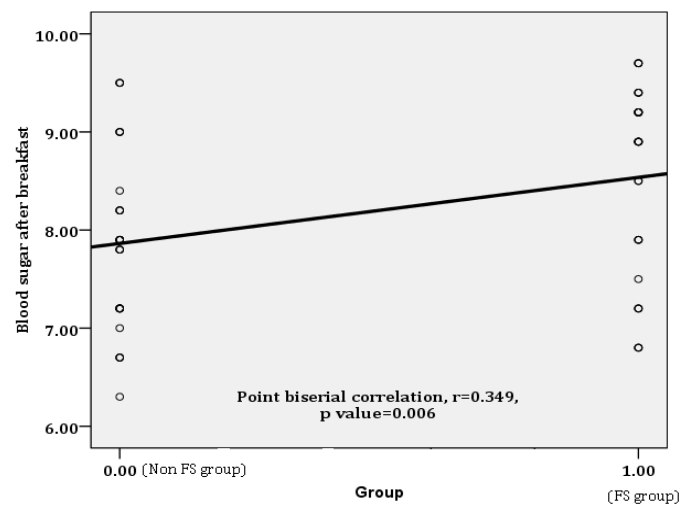

Figure 2: Correlation between blood sugar after breakfast and groups

Here blood sugar after breakfast level is continuous variable and group is a categorical variable $(0=$ Non frozen shoulder [non-FS], $1=$ Frozen shoulder [FS] group). So, Point biserial correlation is appropriate to measure the correlation of above mentioned variables.

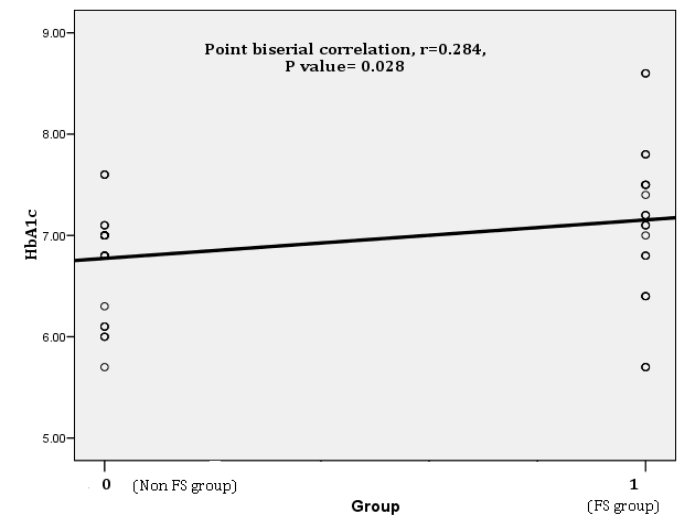

Figure 3: Correlation between $\mathrm{HbA}_{1 \mathrm{c}}$ and groups

Here Glycated haemoglobin (HbAlc) level is continuous variable and group is a categorical variable $(0=$ Non frozen shoulder [nonFS], 1= Frozen shoulder [FS] group). So, Point biserial correlation is appropriate to measure the correlation of above mentioned variables

\section{Discussion}

Frozen shoulder is a condition difficult to define, treat and explain from the point of view of pathology $y^{3}$. The causes of frozen shoulder are largely undetermined. Most of the patients with frozen shoulder are complaints of stiffness and pain in their shoulder joint ${ }^{2}$. Diabetes is a known risk factor for frozen shoulder ${ }^{7}$. In our study both groups had fairly controlled diabetes mellitus, but blood sugar levels, both fasting and 2 hours after breakfast, were significantly higher in frozen shoulder group. Glycated haemoglobin (HbA1c) level was also significantly higher in cases. Lequesne et $\mathrm{al}^{12}$ found an abnormal glucose tolerance test in $28 \%$ patients with frozen shoulder compared with $12 \%$ in control patients. Bridgman ${ }^{13}$ found more patients of frozen shoulder in diabetic group than non diabetic group, and $\mathrm{Pal}$ et $\mathrm{al}^{14}$ reported incidences of $19 \%$ in diabetics and $5 \%$ in non diabetics. In our study positive correlation was observed between incidence of frozen shoulder and blood sugar levels (fasting [ $\mathrm{r}=0.322, \mathrm{p}=0.012], 2$ hours after breakfast $[\mathrm{r}=0.349, \mathrm{p}=0.006]$ and HbA1c $[\mathrm{r}=0.284, \mathrm{p}=0.028]$ ) (Figure: $1,2,3$ )

Uncontrolled diabetes mellitus is one of the most common causes of hypertriglyceridemia ${ }^{15}$. Triglyceride level was normal in our control group $(<150 \mathrm{mg} / \mathrm{dl})$ but in frozen shoulder group mean triglyceride level was $200.13 \mathrm{mg} / \mathrm{dL}$ (SD 21.26) $(\mathrm{p}<0.001)$. In univariate analysis elevated serum triglyceride level was associated with increased risk for frozen shoulder [odds ratio (OR) 3.73, 95\% confidence interval (CI) $2.25-6.18, \mathrm{P}<0.001$ ).

An association between frozen shoulder and diabetes was demonstrated by Bunker and Esler ${ }^{16}$. It appears that hypertriglyceridemia may be associated with frozen shoulder of diabetic patients. Other risk factors should be explored.

\section{Reference}

1. Dias R, Cutts S, Massoud S. Frozen shoulder BMJ 2005; 331:1453-56.

2. Chemeris I, Lathey CD, Niel-Asher S. A presentation of stiff and painful shoulder - a case based Commentary Journal of Osteopathic Medicine, 2004; 7(1): 41-47.

3. Carbone S, Gumina S, Vestri AR and Postacchini R. Coracoid pain test: a new clinical sign of shoulder adhesive capsulitis. Online Journal: International Orthopaedics. 6 May 2009 Available from:www.questia.com/Journals [Access 12/12/2009].

4. Rizk TE, Pinals RS. Frozen shoulder. Seminars Arthritis Rheumatism 1982;11: 440-52. 
5. Sheridan MA and Hannafin JA. Upper extremity: emphasis on frozen shoulder. Orthop Clin North Am. 2006;37(4):531-9.

6. Chambler AFW and Carr AJ. Aspects of current management the role of surgery in frozen shoulder. $\mathrm{J}$ Bone Joint Surg [Br] 2003;85-B:789-95.

7. Kirkness CS, Marcus RL, LaStayo PC, Asche CV, Fritzv JM. Diabetes and Associated Risk Factors in Patients Referred for Physical Therapy in a National Primary Care Electronic Medical Record Database. Phys Ther. 2008;88(11):1408-16.

8. Sarkar RN, Banerjee S, Basu AK, Bandyopadhyay D. Rheumatological manifestations of diabetes mellitus. J Indian Rheumatol Assoc 2003;11: 25-29.

9. Tonino PM, Gerber C, Itoi E, Porcellini G, Sonnabend D, and Walch G. Complex Shoulder Disorders: Evaluation and Treatment. J Am Acad Orthop Surg, 2009;17(3): 125-36.

10. Vermeulen HM, Obermann WR, Burger BJ, Kok GJ, Rozing PM and van den Ende CHM. End-Range Mobilization Techniques in Adhesive Capsulitis of the Shoulder Joint: A Multiple-Subject Case Report. Phys Ther 2000; 80(12): 1204-13.
11. Codman E. Rupture of the supraspinatus tendon and other lesions in or about the subacromial bursa. In: The shoulder. Boston. Thomas Todd, 1934.

12. Lequesne $\mathrm{M}$, Dang $\mathrm{N}$, Bensasson $\mathrm{M}$, Mery $\mathrm{C}$. Increased association of diabetes mellitus with capsulitis of the shoulder and shoulder-hand syndrome. Scand J Rheumatol 1977;6:53-6.

13. Bridgman iF. Penarthritis of the shoulder and diabetes mellitus. Ann Rheum Dis 1972;31:69-71.

14. Pal B, Anderson J, Dick WC, Griffiths ID. Limitation of joint mobility and shoulder capsulitis in insulin- and non-insulin-dependent diabetes mellitus. $\mathrm{Br} J$ Rheumatol 1986;25:147-51.

15. Kolovou GD, Anagnostopoulou KK, Kostakou PM. Primary and secondary hypertriglyceridaemia. Curr Drug Targets. 2009;10(4): 336-43.

16. Bunker D, Esler CAN. Frozen Shoulder and Lipids. J Bone Joint Surg [Br] 1995; 77-B: 684-6. 